\title{
Connecting real learning with social media ROI
}

By: Michael A. Crumpton and Philip B. White

Crumpton, M., \& White, P. (2016). Connecting real learning with social media ROI. The Bottom Line, 29(1), 2-11.

Made available courtesy of Emerald Insight: http://dx.doi.org/10.1108/BL-10-2015-0020

***@@ Emerald Insight. Reprinted with permission. No further reproduction is authorized without written permission from Emerald Insight. This version of the document is not the version of record. Figures and/or pictures may be missing from this format of the document. $* * *$

\begin{abstract}
:
Purpose - This case study aims to outline the activities related to a project to create a foundation for the libraries' social media activities and determine return on investment and value added for the efforts.
\end{abstract}

Design/methodology/approach - This case study describes the actions taken and the information tracked in establishing social media presence with recommendation for a sustainable program. Findings - Social media adds value to libraries' organizational personality, but it also incurs cost and effort that should be strategically managed.

Originality/value - This case study was conducted in the authors' home institution.

Keywords: Social media | Learning | Value | ROI | Curriculum | Graduate student

\section{Article:}

The importance of using social media to promote and market organizations to end-users has risen tremendously over the years, and offerings of formats and programs also continue to increase. Social media can create a competitive advantage for organizations, and, with library organizations, social media acts to build relationships and provide a measure of understanding for organizational purposes and activities. In this regard, social media programs and policies should have a strategic measure of development so as to represent the organization appropriately (Crumpton, 2014).

Furthermore, investment in expertise to facilitate the appropriate distribution of information flow and content can be critical for ensuring that the organizational message is clear and unified. This includes the expertise related to the technologies involved, as it relates to the innovative and social nature of libraries (Vanwynsberghe et al., 2014). Drawing on social network theory research, this Belgium study of library social media practices also concluded that a personal relationship exists between librarians using social media for professional and personal work, thus considering the point of organizational investment in communication expertise. This investment 
might also take the form of training for those who are charged with social media implementation to add credibility and a high degree of ethical concern to their activities (Wasike, 2013).

The University Libraries at the University of North Carolina at Greensboro has partnered with the Department of Library and Information Studies for six years on a learning outcomes-based project called Real Learning Connections. This project creates learning objectives for each partner in a project that provides the opportunity to triangulate learning by all participants. The goals are to incorporate real work with practitioners into the theory presented in the classroom to broaden the perspective of the master of library and information studies (MLIS) graduate student, who will soon be a professional, with a practitioner engaged in the real aspects of the work needed. The faculty component is also important, as it provides feedback to curriculum needs for activities occurring in practice to be current and relevant.

The projects required learning objectives from the faculty supervisor, the librarian supervisor and the student. Progress is documented by reflective journaling, regular meetings and knowledge products created. The Real Learning Connections model benefits the participants, and is an extension of the work to several other initiatives, including incorporation of mentorship into the classroom and extension to virtual internships. The effort to connect practical experience with theory and academic instruction is a long-standing issue in library and information science (LIS) education. LIS educators often enter into an internship relationship with an attitude that the student is the sole locus of learning. This model conveys an interaction between student, practitioner and educator that creates a learning environment for all participants who are expected to meet learning objectives and creates a tangible outcome or product (Figure 1).

This case study highlights the activities and connections made with library science graduate students working with library faculty and LIS faculty on developing and improving on the libraries social media program. Each participant establishes learning objectives for the project to gain knowledge beyond the scope of a tangible project outcome. In the projects, for the two years, the focus has been on establishing the infrastructure for a social media program that lends itself to a consistent message along with measuring the cost and expected effort. What was not part of these projects was the detail given to the content creation for investigating, researching and writing the content to be communicated through social media channels.

\section{Real learning connections, Year 1}

The academic year of 2013/2014 provided an opportunity for a Real Learning Connections project related to social media. This happened at the same time when a social media committee was formed for the libraries to standardize and document social media activities. The LIS graduate assistant for the project became a member of this committee and represented the reference department as total organizational activities were reviewed. The social media committee's mission is to help personnel who lead social media marketing and initiatives at Jackson Library to effectively use social media tools to promote the library's resources and services. The committee will:

- create an inventory of what is currently being done in the University Libraries surrounding social media; 
- collaborate with members of all departments of University Libraries to ensure fair and equal coverage of resources and events;

- benchmark to see what other universities' libraries are doing in this area;

- strive to create a cohesive/integrated look to our social media and marketing efforts;

- provide a timeline and game plan for moving forward with social media in a sustainable manner; and

- develop a policy to quantify the number of postings on various social media sites and develop analytics to assess the use and quality of our postings.

The project learning objectives included participation in this committee and creating an initial plan for developing and publishing content.

In this first year of review and consideration, the strategy was focused on understanding the audience, sharing content regularly and demonstrating your value to encourage people to care about what you have to say. Recommendations from the first year's project included: reviewing program setting for accessibility, streamlining the number of blogs kept and updating content regularly and posting more photographs, as they generated more hits or perceived interest in the topic (O’Connor, 2014).

This first year of a Real Learning Connections project and the feedback received from the social media committee provided the reasoning and opportunity to continue this project with a slightly different focus. It was clear that maintaining an appropriate social media presence required an investment of time and effort, and, although most websites used are free and most payroll expense is absorbed, there are definite costs associated with maintaining a formal program of communication through social media. Therefore, the second year was approved with another LIS graduate assistant to continue the project and research "best practices" for social media activities along with identifying trends related to costs.

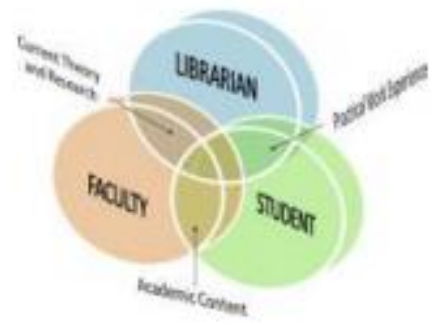

Figure 1. Real learning connections logo

\section{Year 2}

In the spring of 2015, Philip White served as a Real Learning Connections graduate assistant at the Jackson Library at the University of North Carolina at Greensboro. His primary assistantship responsibility was completing an assessment of the library's social media program and managing the library's primary Facebook and Twitter accounts. The project was a year-long review and update to the library's social media platforms. The centerpiece of the work was a semester-long assessment comparing the time and effort put into social media with the amount of student- 
library engagement through Facebook and Twitter and examining the type of content that was most engaged with. As the manager of these two accounts, Philip was well-positioned to assess the time and effort spent on managing the library's social media presence.

Effectiveness of social media efforts is a challenge to pinpoint and evaluate. This is especially true for organizations whose bottom line is not necessarily easy to define, such as an academic library. If we assume that the academic library measures its success by the success of its institution's students and faculty, then the library should, in turn, use social media as a tool for advancing this cause. Following this line of thinking, the library should strategically plan social media content and analyze metrics that allow for gauging return on investment (ROI) of our content. King (2015) identifies one ROI metric for social media as interactions per post created. Measuring how often users interact or engage - click, comment or share - with content tells social media managers how relevant our posts are and guides the social media content strategy. By examining engagement and content-type together, we can actually know what resonates with our social media audience - eliminating guess work.

Facebook and Twitter were the focus of this assessment because of their widespread use among typical college-age students, and they provide comprehensive usage analytics. The two sites are also prevalent in use among academic libraries (Parker, 2013). According to a Pew Research Center study surveying Americans who use the internet, Facebook is used by 71 per cent of internet users - by far the most widely used social media site in the USA (Duggan et al., 2015). The same study found that among the 18- to 29-year-old demographic, 87 per cent use Facebook. Duggan et al. (2015) also reported that Instagram was the second most popular social media site among 18 to 29 year olds with 53 per cent; Twitter was the third most popular in the demographic with 37 per cent. Twitter was chosen for the assessment presented here over Instagram for two reasons. First, the library did not have an Instagram account with established followers, whereas the library's Twitter account had over 500 followers at the onset of the assessment. Second, Twitter provides free monthly analytic data exportable to a spreadsheet for analysis, but Instagram does not provide any analytic information. Facebook also provides free, comprehensive analytic data to its organizational accounts. The ease of access to site analytics coupled with the two sites' prevalent use led to our focus on Facebook and Twitter.

Website analytics are a useful tool for monitoring an organization's influence through social media, and, though the terminology often differs, Facebook and Twitter offer a similar core suite of usage statistics. Farney and McHale (2013) define website analytics as "the process of gathering and interpreting the virtual traffic on a website to learn how users interact with a site" (p. 3). Web developers use analytics to improve a website's usability and utility, identify frequently accessed content and determine how users arrive at the site (Farney and McHale, 2013). Common metrics for social media sites are audience size, activity (i.e. posts or tweets), content views, content engagements and sometimes visitor demographics (King, 2015).

The work completed for this assessment attempted to quantitatively identify the content areas that library employees who manage social media accounts should focus their time on. By correlating the time spent on planning and posting content with user engagement and identifying content types that are most frequently engaged with, Philip identified a relationship between work hours and social media interactions. The study provides a model for other libraries to 
strategically plan a social media program. The overarching goal of the project was to develop a data-informed, strategic plan for moving the library's social media program forward. The project sought to answer the following questions:

Q1. How many work hours are spent both for planning content and engaging with social media?

Q2. Is that time resulting in users actually viewing and engaging with the library on social media?

Q3. What type of content do users most frequently engage with on the library's social media platforms?

Q4. Do users prefer different types of content on different platforms?

In simple terms, the project sought to identify if employee time is well-spent and what type of posts work (and what does not) on social media - particularly for an academic library. The information gained from these efforts would ideally be used to plan the social media content that both serves the end-user (the student) and helps the library to focus efforts on content that works.

\section{Methods}

The assessment began by logging all the time spent working on social media. "Work on social media" entailed several different types of tasks. The most time-consuming of these was gathering and planning content. Content for social media was sourced from the library's events calendar, blogs, news, announcements, library guides and discussions with library staff and faculty. The type of content ranged from simple status updates to photos or links to library Web pages. Some departments within the library had their own social media accounts, which were also sources of content for the primary accounts under Philip's management. Most Facebook posts and tweets were planned ahead of time on a weekly basis and scheduled for specific times during the school week. Philip used the website Hootsuite.com as a scheduling tool. In a typical week, he planned three to five tweets and one to three Facebook posts daily. Most content was separate and unique between the two platforms (i.e. not duplicate posts), although cross-platform posts occurred occasionally. Philip sets aside blocks of time on one or two days a week to do the bulk of social media planning and scheduling, which made tracking time spent on the project easier. At the end of these scheduling sessions, he would record the amount of time spent. At times, opportunities for social media posts came about spontaneously, and he spent a few minutes daily checking on social media to respond to any mentions or interactions that occurred. For these instances, he estimated the amount of time spent and recorded it. All of the time spent was recorded as weekly totals. Tracking time on a finer scale (such as daily or per post) would have been difficult because most of the social media content was organized and planned in scheduled blocks of time. Philip recorded weekly time spent on social media for the 14-week duration of the semester, from January through April, 2015.

At the conclusion of the semester, Philip obtained analytic data from Facebook and Twitter for the library's accounts and identified statistics from the two data sets that were related. 
Facebook's analytic data are branded as Facebook Insights, or Page Insights, and is available to managers of organizational pages. Facebook Insights provides a wealth of analytics, including total post reach, post consumption, post likes, account likes and much more (Facebook.com, 2015). Facebook Insights is easily accessed by clicking the Insights link at the top of the organizational page. Twitter Analytics is Twitter's basic analytics package, which is freely available for any Twitter user account at analytics.twitter.com. For each individual tweet, Twitter provides counts of impressions, engagements, engagement rate, re-tweets, favorites and clicks (Twitter.com, 2015). Both Twitter Analytics and Facebook Insights allow users to export data as a spreadsheet. Included in the spreadsheet are the metrics described above for each post or tweet, along with a timestamp and the text of the post. After downloading and reviewing these data, common key metrics were identified that were provided by both sites such as amount of followers, frequency content is viewed and frequency content is clicked on (Table I).

Philip then grouped each Facebook post and tweet into content categories and examined how frequently users engaged with posts in different categories. At the onset of the project, he reviewed other academic libraries' social media feeds and identified three broad categories of posts: news and updates (news), event announcements (events) and links to library website content (content links). The weekly content was posted with these categories in mind, which made assigning a category to each tweet and Facebook post at the end of the semester easier. Content in the news category typically consisted of goings on about the library (announcements, new exhibits, holiday hours, weather closures, etc.). Events' posts were related to upcoming workshops, lecture series, film screenings and one-time events, such as Game Night. Posts that contained links back to library Web content (libguides, blog posts, collections or other library department social media pages) were classified as content links. Using the analytics data downloaded from Facebook and Twitter, Philip calculated the average amount of engagements and views per post for each category for both social media platforms. The Average amount of engagement for each category would allow for easy identification of the type of social media content that was most popular with our followers.

Finally, the relationship between post/tweet engagement and the time spent on planning and posting social media content was examined. Because time was recorded in weekly intervals, Philip totaled the amount of weekly views and engagements that occurred on both platforms for the purpose of comparison. With a goal of gauging ROI in mind, Philip calculated Pearson product-moment correlation coefficients (r values) to identify relationships between time spent and user engagements. The correlation analysis sought to answer the following question: "Is this time well-spent?" It should be noted that the small amount of observations (14 weeks) precluded a robust statistical analysis. Despite this barrier, correlation analysis was conducted to gain a better sense of the return on the time investment of social media and to provide future direction for the social media program.

\section{Results and discussion}

During the 14-week period, Philip tweeted 329 times and posted content on Facebook on 131 occasions. These efforts translated to about 23 tweets and 9 Facebook posts each week. These results fall within the range of posts-per-week goals established at the onset of the project. These results were easy to achieve with even a relatively low amount of work hours. The actual time 
spent on planning and organizing social media content was less than expected. Over the 14-week period of measurement, the average time committed to planning and engaging in social media activities was $98.92 \mathrm{~min}$ per week ( $23 \mathrm{~h}$ and $5 \mathrm{~min}$ for the semester). The highest weekly total time spent was $180 \mathrm{~min}$, while the lowest was 30 min during the week of spring break. These results indicate that libraries' social media managers can maintain a consistent stream of social media content by planning and organizing the majority of posts ahead of time. Setting aside weekly time to plan content coupled with daily check-ins was an effective time management strategy that others should use.

\begin{tabular}{llll}
\hline $\begin{array}{l}\text { Social } \\
\text { media } \\
\text { platform }\end{array}$ & $\begin{array}{l}\text { Feed } \\
\text { subscribers }\end{array}$ & Content views & Content engagement/clicks \\
\hline Facebook & Likes & $\begin{array}{l}\text { Reach (number of times } \\
\text { people are served a post) } \\
\text { Impressions (number of times } \\
\text { users are served a tweet) }\end{array}$ & $\begin{array}{l}\text { Consumptions (number of clicks } \\
\text { anywhere in a post) } \\
\text { Engagements (number of times } \\
\text { users clicked anywhere on the } \\
\text { tweet) }\end{array}$ \\
\hline
\end{tabular}

Table I. Terminology of common key metrics provided by Facebook Insights and Twitter Analytics

Different types of content proved to be more effective from one social media site to the other. While it is difficult to directly compare Facebook and Twitter figures because of differences in the platforms, one can see what types of content was most popular on each. Content links (i.e. hyperlinks to content on the library website) were by far the most popular category of posts on Facebook. Facebook posts that included links to the library's website averaged about nine engagements each - triple the amount of engagements per post for events (Figure 2). News posts were engaged with minimally on Facebook, which is logical considering that news posts did not often contain clickable hyperlinks. However, the news category was most frequently engaged with on Twitter followed by content links (Figure 3). News tweets were frequently re-tweeted by other Twitter users, particularly other university accounts, as a way of disseminating information. The differences in category engagements on the two platforms suggest that Twitter should be considered first for news and update-oriented content, while Facebook may be more useful for linking to the library website. Overall, social media users engaged with content much more frequently on Facebook on average, although some news tweets reached levels of engagement that were on par with typical Facebook posts.

ROI was difficult to gauge, but given a relatively low amount of work hours devoted to managing the two accounts, investment was actually quite low. The correlation results of the minutes spent per week with the number of weekly engagements and views were not statistically significant (likely due to the low sample size), but provided some direction for future social media efforts. The most interesting result was the stronger relationship between time spent and engagement on Facebook than Twitter. The correlation coefficient between time spent and engagement on Facebook was $r=0.48$, while the same relationship on Twitter was 0.34 (Table II). These results are inconclusive, but they suggest that a stronger relationship may exist between user engagement and time spent on Facebook than Twitter. If direction can be taken 
from these analyses, then one could speculate that time spent on Facebook is more productive than that on Twitter because users are more engaged with the content. Further, long-term analysis is needed to gain a clearer picture of the true relationship between employee effort and user engagement on social media.

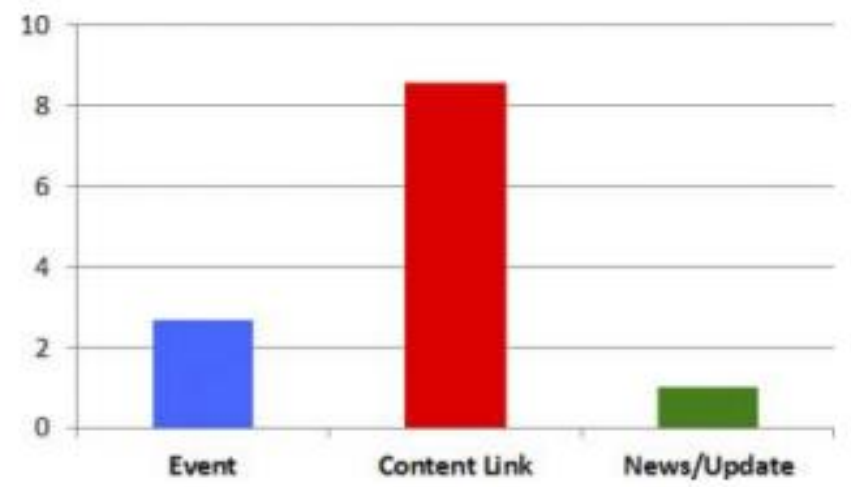

Figure 2. Average Facebook post engagement by category

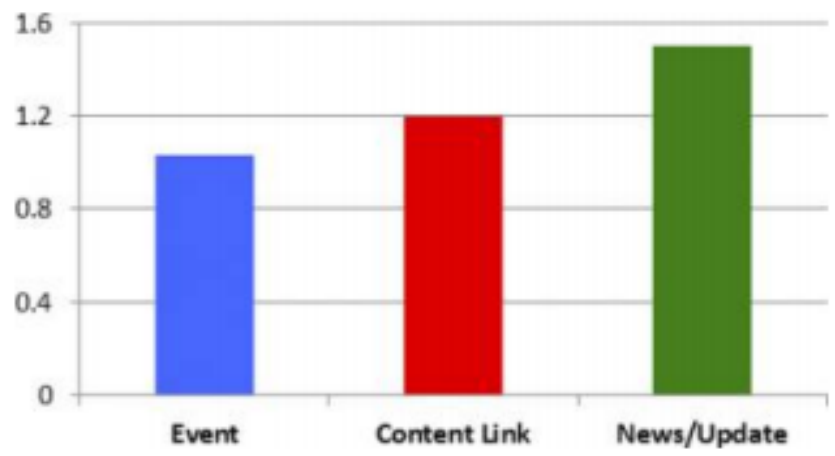

Figure 3. Average tweet engagement by category

Considering that Facebook and Twitter are freely available for use, the monetary investment, aside from worker compensation, is nothing. Following the conclusion of this research, responsibilities passed to an employee in a support staff role. According to the Bureau of Labor Statistics, the average pay for library technicians and assistants working at colleges and universities in 2012 was $\$ 15.47$ per hour (USA Department of Labor, 2014). That salary applied to the average weekly time spent on social media in this study ( $1 \mathrm{~h}, 38 \mathrm{~min})$, breaks down to $\$ 25.21$ of worker compensation paid weekly for social media (\$353.02 total for a 14-week semester). One should also note that these time measurements took place during the semester, and work hours spent on social media would presumably drop during inter-semester periods. Even in times of fiscal restraint, $\$ 350$ per semester is a small investment for an academic library. With such a low investment, even small amounts of publicity gained from social media can be considered a net positive.

Further examination of website metrics could produce a more complete view of social media ROI. While this case study provided insight into investment in terms of work hours, the logical next step will be reviewing analytic metrics of the library website to determine how frequently 
the site's visitors arrive through social media pathways. Links to library website content were often engaged with on both Facebook and Twitter. One could presume that these engagements led to visits to the library website, but website analytics would provide hard evidence that website visitors arrive as a direct result of a Facebook post or tweet. Considering the critical nature of academic library's websites, the effectiveness of social media platforms in delivering users to the library's Web content should be considered moving forward.

The case study presented here provided direction for the library's social media content strategy and demonstrated the first step in gauging social media ROI. By setting aside blocks of time devoted to planning and scheduling social media content, we efficiently managed a consistent social media presence for the library. One to two hours each week, consisting of blocks of time and periodic check-ins, was the typical amount of time needed to manage the library's social media accounts. Others may find that more or less time is needed, but this amount of time worked for our library. The relationship between the actual time spent on managing social media accounts and user engagement on Twitter and Facebook was unclear, but the monetary investment in managing social media is low. Hyperlinking to content from the library's website was the most engaged-with category of posts on Facebook, and the second most engaged-with category on Twitter. Content related to news was much more popular on Twitter than on Facebook. These results suggest that content planned for Facebook and Twitter should be unique to the two platforms, with links to the library's website prioritized for Facebook. The project succeeded in developing informed social media practices in the library and prepared a foundation for future data gathering and review.

\begin{tabular}{llc}
\hline Social media platform & $r$ value & $p$ value \\
\hline Facebook & $r=0.48$ & $p=0.08^{\mathrm{a}}$ \\
Twitter & $r=0.34$ & $p=0.23^{\mathrm{a}}$ \\
Note: ${ }^{a}$ Results were not statistically significant & & \\
\hline
\end{tabular}

Table II. Results of Pearson product-moment correlation of weekly minutes spent working on social media and average weekly engagements on Facebook and Twitter

These results are consistent with other studies, in that the investment in using social media as an information dissemination tool can be low (Romero, 2011) and is a good activity to practice by small- and medium-size libraries. However, for this investment to be useful, care must be taken to be consistent with posting and diverse in obtaining content from within the organization. Policies should be written that provide measurement for social media usefulness and guidelines for posting ethically (Kiser, 2015). These Real Learning Connections projects launched our organization into a higher level of social media use and are intended to provide ongoing improvement and effectiveness for carrying our message.

\section{Conclusions and learning outcomes}

Both project years were considered successful and the tangible project results are meaningful. 
Based on the work to research and develop an environmental scan for best practices, the libraries has a new Facebook page with an increased number of followers, and the Twitter account is deemed more professional and also has an increased following. The students input for the social media program provided a solid foundation for activity and assessment, and students both graduated and obtained professional positions immediately.

Philip's recommendations, in turning the work back over the librarians and staff to continue, included:

- be active with two to three posts each day per social media platform;

- $\quad$ prioritize Twitter for news and updates and use Facebook for events and links;

- increase promotion of social media sites around the library physically to increase awareness and followers;

- designate specific personnel with social media maintenance responsibility; and

- investigate other platforms and review analytics to determine trends and efficiencies.

Librarian supervisors and staff involved with the projects and the social media committee were reminded of how quickly technology changes and needs constant attention to remain current and relevant to end users, especially students. Also, understanding the social media landscape is important to recognize trends that matter to usefulness and effectiveness of the efforts made. The LIS faculty also recognized the need to address social media with greater emphasis in the curriculum of related courses.

Future projects could look at investment in content creation. The investment was low for these projects which used content of a quick announcement or event planning nature, but more indepth content stories and experiences require another level of investment, added to the management of the online platform for ROI purposes. The libraries have since maintained the work started and have looked for ways to expand and measure the effectiveness of social media efforts.

\section{References}

1. Bird, N. and Crumpton, M.A. (2014), "Real learning connections: questioning the learner in the LIS internship", Journal of Education for Library and Information Science (JELIS), Vol. 55 No. 2, pp. 89-99.

2. Crumpton, M.A. (2014), "Leading results: accounting for the cost of social media", The Bottom Line: Managing Library Finances, Vol. 27 No. 3.doi: 10.1108/BL-06-2014-0017.

3. Duggan, M., Ellison, N.B., Lampe, C., Lenhart, A. and Madden, M. (2015), Social Media Update 2014, Washington, DC.

4. Facebook.com (2015), About Page Insights, available at: www.facebook.com/help/336893449723054/ 
5. Farney, T. and McHale, N. (2013), Web Analytics Strategies for Information Professionals: A LITA Guide, ALA Editions, New York, NY, available at: http://site.ebrary.com/lib/uofw/docDetail.action?docID=10788467\&ppg=13

6. King, D.L. (2015), “Analytics, goals, and strategy for social media”, Library Technology Reports, Vol. 51 No. 1, pp. 26-32.

7. Kiser, G. (2015), "Tips for creating a social media policy”, CUPA-HR Higher Education Workplace Blog.

8. Romero, N.L. (2011), "Roi. Measuring the social media return on investment in a library", The Bottom Line: Managing Library Finances, Vol. 24 No. 2, pp. 145-151.

9. O'Connor, K. (2014), "Establishing a social media presence in an academic library", Real Learning Connections Project Reports, University Libraries, Greensboro.

10. Twitter.com (2015), About Analytics, available at: https://analytics.twitter.com/about

11. United States Department of Labor (2014), Library Technicians and Assistants: Occupational Outlook Handbook, US Bureau of Labor Statistics, available at: www.bls.gov/ooh/education-training-and-library/library-technicians-andassistants.htm\#tab-5

12. Vanwynsberghe, H., Boudry, E., Verdegem, P and Vanderlinde, R. (2014), "Experts as facilitators for the implementation of social media in the library? A social network approach", Library Hi Tech, Vol. 32 No. 3, pp. 529-545.

13. Wasike, J. (2013), "Social media ethical issues: role of a librarian”, Library Hi Tech News, Vol. 30 No. 1, pp. 8-16. 